\title{
Análisis del tostado del grano de café
}

\section{Analysis of coffee grain roasting}

\author{
RAMÍREZ-ROMÁN, Adolfo†*, SUÁREZ-ÁLVAREZ, Ángel, CHABAT-URANGA, Jacqueline y \\ ORTIZ-MARTÍNEZ, Francisco
}

Universidad Veracruzana, Facultad de Ingeniería Mecánica y Ciencias Navales

ID $1^{\text {er }}$ Autor: RAMÍREZ-ROMÁN, Adolfo / ORC ID 0000-0002-3820-8582, Researcher ID Thomson: S-5868-2018, arXiv Author ID: adolramirez, PubMed DI: adolramirez, CVU CONACYT ID: 244749

ID 1 ${ }^{\mathrm{er}}$ Coautor: SUÁREZ-ÁLVAREZ, Ángel / ORC ID: 0000-0002-0726-9630, CVU CONACYT ID: 946964

ID $2^{\text {do }}$ Coautor: CHABAT-URANGA, Jacqueline / ORC ID: 0000-0003-2202-1032, CVU CONACYT ID: 464993

ID $3^{\text {er }}$ Coautor: ORTIZ-MARTÍNEZ, Francisco / ORC ID: 0000-0003-3722-7658, CVU CONACYT ID: 998622

DOI: $10.35429 / J I E .2019 .10 .3 .1 .16$

Recibido 04 de Noviembre, 2019, Aceptado, 03 de Diciembre, 2019

\begin{abstract}
Resumen
Analizar las operaciones de tostado del grano de café Región de Veracruz contribuirá en la distribución de los equipos y maquinaria en el taller de Ingeniería Industrial del Programa Educativo. Tiene la finalidad de obtener mejoras en el proceso de tostado a través del estudio del trabajo (Enero - Junio 2019), para sentar bases en las propuestas de Sistemas de Gestión de la Calidad, Seguridad y Cuidado del Ambiente en las siguientes etapas del proyecto (2019-2020) con efectos en la mejora continua. En la industria del café en México tiene en el mediano y largo plazo, oportunidades para crecer y consolidación. Como sucede con la mayoría de los productos agrícolas de los minifundios, como es el caso del café, los precios que se pagan por el insumo ("café cereza") distan mucho de lo que el café procesado llega a obtener en presentaciones de polvo soluble y molido para las cafeteras, y es necesario el proceso de mejora, de calidad, de eficiencia en las actividades del tostado. En el método se analizó el estudio de casos de las operaciones de empresas, productores y de investigación relacionadas con el sector industrial cafetalero y caficultor, e interpretación de los resultados estadísticos.
\end{abstract}

Grano de café, Tostado, Análisis

\begin{abstract}
Analyzing coffee grain roasting operations - Veracruz Region will contribute to the distribution of equipment and machinery in the Industrial Engineering workshop of the Educational Program. It aims to obtain improvements in the roasting process through the study of the work (January-June 2019), to lay the foundation for the proposals of Systems of Quality Management, Safety and Environmental Care in the following phases of the project (2019-2020) with effects on continuous improvement. In the coffee industry in Mexico has in the medium and long term, opportunities to grow and consolidate. As with most agricultural products from smallholders, such as coffee, the prices paid for the input ("cherry coffee") They are far from what the processed coffee comes to obtain in presentations of soluble and ground powder for coffee makers, and the process of improvement, quality, efficiency in roasting activities is necessary. The method analyzed the case studies of the operations of companies, producers and research related to the coffee and coffee industry and the interpretation of the statistical results
\end{abstract}

Coffee bean, Roasted, Analysis

Citación: RAMÍREZ-ROMÁN, Adolfo, SUÁREZ-ÁLVAREZ, Ángel, CHABAT-URANGA, Jacqueline y ORTIZMARTÍNEZ, Francisco. Análisis del tostado del grano de café. Revista de Ingeniería Industrial. 2019 3-10: 1-16

\footnotetext{
* Correspondencia del Autor (Correo electrónico: adolramirez@uv.mx)

$\dagger$ Investigador contribuyendo como primer autor.
} 


\section{Introducción}

El presente artículo es parte de cuatro fases con referencia a los objetivos particulares (corto, mediano y largo plazo) indicados en la tabla 01 , con la finalidad de obtener mejoras en el proceso de tostado, molienda, envasado del café, a través del estudio del trabajo e ingeniería de métodos, para sentar bases en las propuestas de Sistemas de Gestión de la Calidad, Seguridad y Cuidado del Ambiente con fecha de inicio de 01 agosto de 2018 y fecha de término en 30 de noviembre de 2020, y se complementa con el uso de la mesa rotatoria y equipos de medición del área de ergonomía.

Con este proyecto de Investigación se tiene un Impacto en las líneas de investigación del CA: Gestión e Innovación de las operaciones con el desarrollo de sus objetivos particulares y acciones indicadas en la tabla 01 .

\begin{tabular}{|l|l|l|l|}
\hline \multicolumn{1}{|c|}{$\begin{array}{l}\text { Objetivo } \\
\text { particular }\end{array}$} & \multicolumn{4}{|c|}{ Acción 1 } \\
\hline $\begin{array}{l}\text { Distribución } \\
\text { de los equipos } \\
\text { y maquinaria }\end{array}$ & $\begin{array}{l}\text { Aplicación de } \\
\text { las metodologías }\end{array}$ & $\begin{array}{l}\text { Determinación } \\
\text { de la ruta } \\
\text { crítica y la } \\
\text { efectividad }\end{array}$ & $\begin{array}{l}\text { Diseño de } \\
\text { lay-out }\end{array}$ \\
\hline $\begin{array}{l}\text { Análisis de la } \\
\text { operación del } \\
\text { proceso }\end{array}$ & $\begin{array}{l}\text { Elaboración de de Estudio de } \\
\text { trabajo }\end{array}$ & $\begin{array}{l}\text { Aplicación de } \\
\text { herramientas } \\
\text { de la calidad y } \\
\text { productividad }\end{array}$ & $\begin{array}{l}\text { Manual de } \\
\text { operación }\end{array}$ \\
\hline $\begin{array}{l}\text { Determinación } \\
\text { de un sistema } \\
\text { de gestión }\end{array}$ & $\begin{array}{l}\text { Análisis del } \\
\text { contexto de la } \\
\text { organización }\end{array}$ & $\begin{array}{l}\text { Identificación } \\
\text { de procesos } \\
\text { claves }\end{array}$ & $\begin{array}{l}\text { Propuesta } \\
\text { de gestión }\end{array}$ \\
\hline $\begin{array}{l}\text { Gestión de } \\
\text { servicio } \\
\text { colaborativo } \\
\text { con el sector } \\
\text { cafetalero }\end{array}$ & $\begin{array}{l}\text { Consolidación } \\
\text { de Convenios } \\
\text { con empresas } \\
\text { cafetaleras }\end{array}$ & $\begin{array}{l}\text { Capacitación } \\
\text { del personal }\end{array}$ & $\begin{array}{l}\text { Consolidar } \\
\text { la relación } \\
\text { con } \\
\text { proyectos } \\
\text { académicos }\end{array}$ \\
\hline
\end{tabular}

Tabla 01 Resumen de objetivos particulares y acciones Fuente: Elaboración propia

En dicho artículo conformado por las secciones de entorno, operación, generación de información, anexo, agradecimiento, conclusiones y referencias.

Se describen los resultados de la primera etapa Enero - Marzo 2019 y de la segunda etapa en el periodo de Abril-Junio 2019, con referencia al tiempo de operación del tostado del grano de café verde en la máquina tostador de $3 \mathrm{~kg}$ por ciclo de capacidad (Ver figura 1 ).

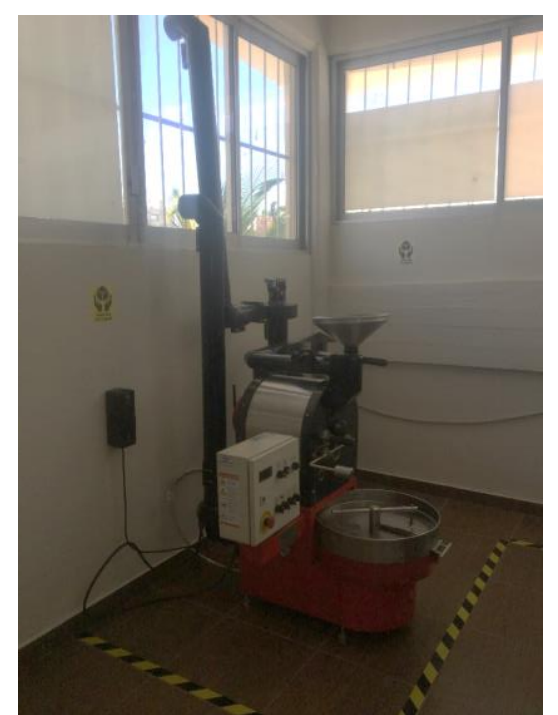

Figura 1 Tostador $3 \mathrm{Kg} / \mathrm{Ciclo}$

Fuente: Laboratorio de Ingeniería Industrial de la Universidad Veracruzana

La SAGARPA (Secretaría de Agricultura, Ganadería, Desarrollo Rural, Pesca y alimentación) determinó que el café es la segunda bebida más consumida en el mundo, sólo después del agua. En nuestro país se produce el aromático en poco más de una docena de entidades federativas, siendo Chiapas y Veracruz los que aportan la mayor parte de la cuota, poco más del $80 \%$.

El café que se produce en México se exporta a los Estados Unidos, Canadá, Países de la Unión Europea, Japón y otros, también se consume en el mercado interno, enfrentando a la competencia de importaciones de Brasil, Vietnam y Colombia principalmente; el consumo nacional per cápita es de $1.6 \mathrm{~kg}$, siendo considerado el café una bebida estimulante con propiedades antioxidantes y que favorece la digestión.

En el estado de Veracruz se destinan aproximadamente 115630 hectáreas para el cultivo anual de café, y la producción que se obtiene es de poco más de 60, 000 toneladas, en las diez regiones cafetaleras consideradas: Zongolica, Tezonapa, Córdoba, Huatusco, Coatepec, Atzalan, Misantla, Papantla, Chicontepec y los Tuxtlas, las cuales incluyen 40 municipios.

El café se obtiene del cultivo de la Planta Coffea Arábica L. y el proceso incluye la industria extractiva (agrícola), de transformación y la de servicios, de ahí la importancia social y económica que esta actividad representa, al igual que la petrolera, la turística, la ganadera y la de los cítricos.

RAMÍREZ-ROMÁN, Adolfo, SUÁREZ-ÁLVAREZ, Ángel, CHABATURANGA, Jacqueline y ORTIZ-MARTÍNEZ, Francisco. Análisis del tostado del grano de café. Revista de Ingeniería Industrial. 2019 
Gran parte de la producción que llega a ser comercializada se encuentra concentrada en unos cuantos mayoristas, mientras que los pequeños productores que representan cerca del $90 \%$ del gremio, se limitan a la parte del cultivo y la obtención del café seco. En los últimos 10 años la producción de café en el país, ha venido a la baja (- sustitución del cultivo por caña de azúcar, la plaga de la roya-) con las respectivas consecuencias que tienen para los pequeños productores ejidatarios, no obstante en la pasada exposición en febrero de 2018 "Expo Café \& Gourmet Guadalajara", se estimó que al final de este año se obtengan 270, 000 toneladas y al plazo del año 2020, se estiman 420,000 toneladas, lo que vislumbra una oportunidad para los productores nacionales del aromático. Por ello, la aplicación de los conocimientos de la ingeniería en el sector cafetalero es fundamental para la sostenibilidad explícita o implícita en la dimensión social, natural y financiera de la Región de Veracruz.

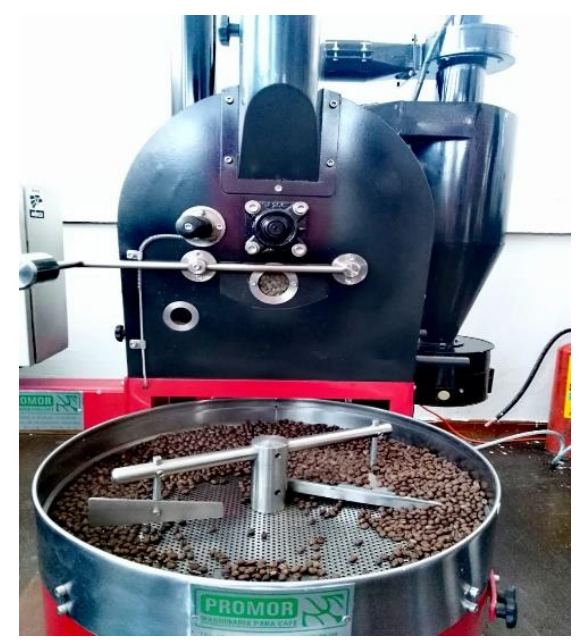

Figura 2 Enfriado de Grano de café tostado Fuente: Laboratorio de Ingeniería Industrial de la Universidad Veracruzana

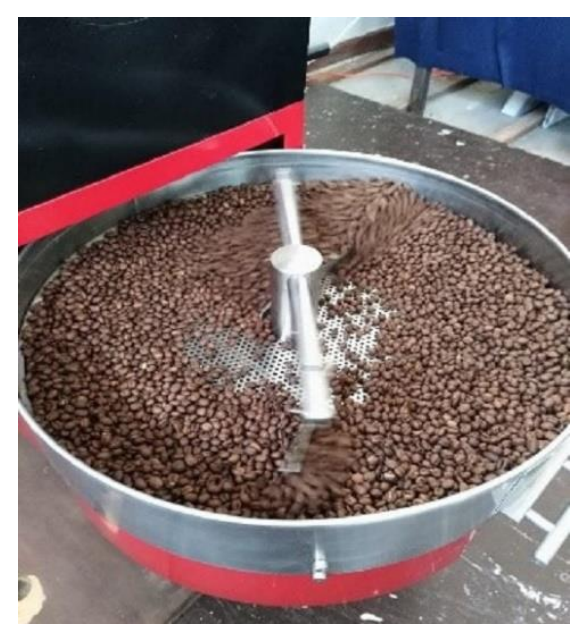

Figura 3 Grano de café tostado

Fuente: Laboratorio de Ingeniería Industrial de la Universidad Veracruzana
La Universidad Veracruzana, como institución que ejerce entre sus funciones sustantivas la extensión, tiene un compromiso con el desarrollo social, cultural y económico en su entorno local, estatal y nacional (Programa de Trabajo Estratégico 2017 - 2021). Uno de los diversos medios que la Universidad posee para dar respuesta a tal compromiso, son los Cuerpos Académicos (UV-CA-470); estos grupos de docentes e investigadores, tienen como propósito contribuir al desarrollo de la institución a través de las líneas de Generación y Aplicación del Conocimiento, teniendo en cuenta los objetivos y los Programas Educativos (PE Ingeniería Industrial) de las Entidades Académicas de la Universidad, así como la pertinencia de su contribución a la solución de problemas sociales y productivos.

La manufactura y desarrollo de una gestión que es apoyada con el conocimiento empírico, con sus respectivos altos costos, su eficacia en la productividad y $\sin$ la determinación de los parámetros de calidad, de la planeación industrial e impacto ambiental de las operaciones industriales y comerciales del Café en Veracruz, también, del control paralelo en avance de la tecnología; por lo que el objetivo general de la presente propuesta consiste en analizar y evaluar las operaciones e innovaciones del proceso productivo del café y permita la gestión e implementación de los equipos del taller de Ingeniería de Métodos de acuerdo al marco de referencia 2018 del Consejo de Acreditación de la Enseñanza de la Ingeniería, A.C. "CACEI" y de los requerimientos de Comités Interinstitucionales para la Evaluación de la Educación Superior "CIEES".

El sector es amplio, va de lo extractivo hasta la comercialización, pasando por la transformación, de ahí que este equipo de trabajo de la Facultad de Ingeniería Mecánica y Ciencias Navales "FIMCN" de la Universidad Veracruzana busque incidir en una parte de la cadena, específicamente la que involucra el tostado, molienda y envaso como primera etapa, misma que se busca modelar en laboratorio, por lo cual es necesario el equipo para reproducir las operaciones, y así, poder estudiarlas, replicarlas y proponer estándares.

Es un sector de alta importancia social y económica, que ofrece trabajo a medio millón de familias. 
En los municipios cafetaleros, siete de cada diez habitantes viven en condiciones de marginación, alta correlación con la pobreza, tres de cada cuatro trabajadores agrícolas, no perciben ingresos o generan hasta un salario mínimo. Por tanto, en la institución existe la necesidad de:

- Fortalecimiento del laboratorio de ingeniería industrial con los criterios del marco de referencia CACEI 2018 y criterios de CIEES en el Programa Educativo de Ingeniería Industrial.

- Mejorar o innovar los procesos y procedimientos de la industria del café.

- Cuidar la salud del trabajador en su espacio de labores.

- Fomentar el ahorro en materia prima, energía y recurso humano.

- $\quad$ Fortalecer las estrategias de vinculación y extensión de los Programas Educativos Involucrados en el Cuerpo Académico.

Fortalecer y diversificar los convenios con las empresas de sector cafetalero a través de la vinculación y extensión de los estudiantes y docentes.

- Estandarizar el conocimiento empírico a través de los cursos, seminarios y diplomados generados en Educación Continua de la Facultad en pro de las necesidades del personal involucrado en la industria del café.

- La consolidación de espacio de análisis de la operación para que los estudiantes generen trabajo de investigación a partir del modelo de referencia del sector del café en otros sectores industriales.

\section{Entorno}

La incidencia de este proyecto presentado en el Programa Educativo dará un impulso a la investigación dentro del cuerpo Académico (CA) en grado de Formación: "Innovación en Sistemas de Gestión" con clave PROMEPSEP.UV-470 y con la colaboración del CA en Consolidación con Clave PROMEP-SEP-UV341 "Ingeniería de Procesos y Desarrollo sustentable" los cuales presentamos.

La competitividad en una empresa proviene del funcionamiento adecuado de la misma, esto es, que todas sus áreas que la constituyen (producción, finanzas, marketing, entre otras ramas interdisciplinarias) operen con eficacia y eficiencia.
Se define la eficacia como "la obtención de los resultados deseados", y a la eficiencia, como "el obtener el resultado deseado con el mínimo posible de insumos".

Gran parte de la producción que llega a ser comercializada se encuentra concentrada en unos cuantos mayoristas, mientras que los pequeños productores que representan cerca del $90 \%$ del gremio, se limitan a la parte del cultivo y la obtención del café seco. En los últimos 10 años la producción de café en el país, ha venido a la baja (- sustitución del cultivo por caña de azúcar, la plaga de la roya-) con las respectivas consecuencias que tienen para los pequeños productores ejidatarios, no obstante en la pasada exposición en febrero de 2018 "Expo Café \& Gourmet Guadalajara", se estimó que al final de este año se obtengan 270,000 toneladas y al plazo del año 2020, se estiman 420,000 toneladas, lo que vislumbra una oportunidad para los productores nacionales del aromático. Por ello, la aplicación de los conocimientos de la ingeniería en el sector cafetalero es fundamental para la sostenibilidad explícita o implícita en la dimensión social, natural y financiera de la Región de Veracruz. "Se han generado tecnologías para recolección del café, para el beneficio ecológico del café por vía húmeda con reducción en el consumo de agua y control de la contaminación de más del 90\%; así mismo, se han entregado tecnologías apropiadas para el secado solar y mecánico de café." (Oliveros-Tascón, C. E., \& Sanz-Uribe, J. R. 2011).

El sector es amplio, va de lo extractivo hasta la comercialización, pasando por la transformación, de ahí que este equipo de trabajo de la Facultad de la Universidad Veracruzana busque incidir en una parte de la cadena, específicamente la que involucra el tostado, molienda, envasado y comercialización, misma que se busca modelar en laboratorio, por lo cual es necesario el equipo para reproducir las operaciones, y así, poder estudiarlas, replicarlas y proponer estándares.

Como resultados del diseño y aplicación del modelo de administración para la operación sustentable y gestión de la calidad en las agroindustrias de café del municipio de Coatepec, Veracruz; de la estrategia de despliegue y desarrollo se obtiene la mejor técnica en el secado de café, lográndose una disminución en los costos, en el tiempo de operación y mejoría en los parámetros de calidad.

RAMÍREZ-ROMÁN, Adolfo, SUÁREZ-ÁLVAREZ, Ángel, CHABATURANGA, Jacqueline y ORTIZ-MARTÍNEZ, Francisco. Análisis del tostado del grano de café. Revista de Ingeniería Industrial. 2019 
Otro de los resultados es el diseño y aplicación del modelo de evaluación para los beneficios de café el cual permite determinar la situación actual del desempeño para la planeación de la estrategia de desarrollo.

Se involucran Experiencias Educativas con horas prácticas para desarrollar en los estudiantes la capacidad de analizar y aplicar los conocimientos teóricos fortaleciendo el perfil de egreso y su respectivas competencias con apoyo de software pertinente, y así optimizar la gestión enseñanza - aprendizaje con impacto en la experiencia del alumno con el sector industrial a partir del análisis y simulación del proceso productivo referente del sector cafetalero con sus equipos, maquinaria y su respectiva variedad de granos a analizar en el laboratorio - taller de Ingeniería Industrial para fortalecer la innovación de las operaciones que involucra la selección, tostado, molienda, empaquetado y distribución del café como modelo de negocio para replicar en otros sectores tradicionales o regionales del Estado de Veracruz.

\section{Operación}

Las relaciones económicas y socioculturales que se establecen en torno a la producción de café. Se centra en las estrategias de los pequeños productores de una región del centro de Veracruz, México, orientadas a enfrentar los cambios suscitados en el sector durante los últimos años. Establece que la variedad de prácticas productivas se relaciona con los modos específicos de concebir el café, y que tales formas de pensamiento y de práctica se han ido construyendo socialmente, en el marco de un contexto histórico-social, local y regional, a partir de la experiencia y la posición de los pequeños productores en la cadena productiva. (Mendoza, 2009).

Se identifican, dentro de la variedad de respuestas individuales $\mathrm{y}$ familiares, dos tendencias generales, dos modos de trabajar y pensar el café, asociados a dos esquemas productivos, uno especializado $\mathrm{y}$ otro diversificado.

Para caracterizar estas dos tendencias, el artículo describe -a manera de comparación- las estrategias desarrolladas por los productores de dos localidades de la región, y cómo estas estrategias les permiten mantenerse como cafetaleros.
Esta diversidad de estrategias coloca a los productores en posiciones distintas frente a las actuales dinámicas del mercado internacional -que dejó de estar regulado y pasó a organizarse como oligopolio-, tendiente a la segmentación e influido por nuevos patrones de consumo.

Las reflexiones finales señalan la relevancia de la organización cafeticultora para promover el escalamiento de su producto tras poner en práctica las estrategias productivas de los mercados alternativos para el desarrollo de la localidad, priorizando los objetivos productivos y relegando los objetivos sociales y medioambientales. Sin embargo, los impactos económicos en el individuo inciden indirectamente en el desarrollo de la comunidad. En general, la organización debe balancear su gestoría en el desarrollo local para obtener resultados positivos multidireccionales. [ABSTRACT FROM AUTHOR] (del Carmen CamasPascacio, A., \& Velázquez-Pompeyo, R. I. 2014)

\section{Generación de información}

La información obtenida durante el proceso de tostado en el periodo de Enero - Marzo 2019 se tienen los siguientes elementos: Número de operación, fecha, hora de inicio, hora vaciado (Ver ejemplo en Figura 23), cambio de color en el grano, hora salida grano tostado, enfriado, molido, fin de molido, fin de proceso, cantidad, temperatura mínima y máxima, tiempo total, peso inicial, peso final.

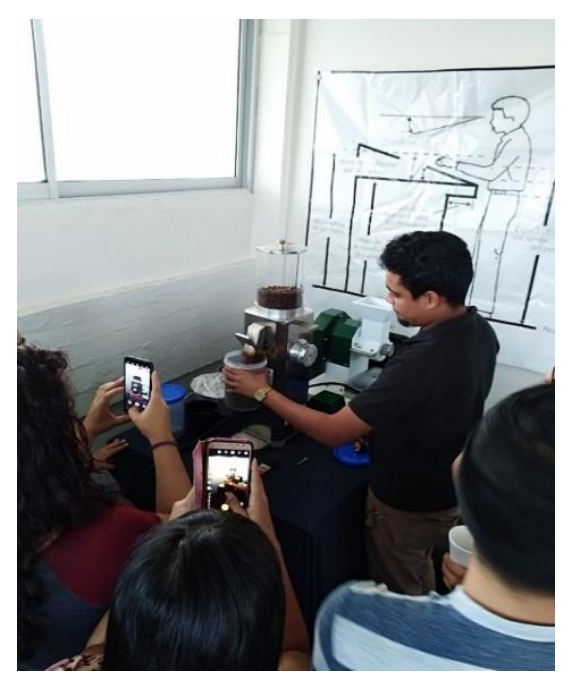

Figura 4 Operación de molido

Fuente: Elaboración propia

El grano de muestra es identificado como Café verde de Córdoba 30 caballeros de altura. 
Las dimensiones promedio en $\mathrm{mm}$ del grano utilizado en las pruebas fueron los siguientes:

Altura $=3.79 \mathrm{~mm}$

Ancho $=7.14 \mathrm{~mm}$

Largo $=9.87 \mathrm{~mm}$

$$
\begin{aligned}
& \text { Altura }=4.56 \mathrm{~mm} \\
& \text { Ancho }=7.20 \mathrm{~mm} \\
& \text { Largo }=11.16 \mathrm{~mm}
\end{aligned}
$$

Por el cual, en las operaciones ejecutadas se tiene: 17 gramos de grano verde, equivale a 187 granos. Y, 33 gramos de grano tostado, equivale a 235 granos.

En las siguientes tablas, se muestra el resultado con relación a un promedio de los elementos mencionados y analizados en las muestras para tres operaciones con su fecha respectiva:

\begin{tabular}{|l|c|l|l|}
\hline \multicolumn{4}{|c|}{ Datos de muestras de $3 \mathrm{~kg} /$ ciclo en cada operación } \\
\hline Elemento / Operación & $\mathbf{1}$ & $\mathbf{2}$ & $\mathbf{3}$ \\
\hline Fecha & 18 Enero & 8 Febrero & 8 Marzo \\
\hline Tiempo de Inicio & $09: 25$ & $10: 10$ & $09: 30$ \\
\hline Vaciado & $09: 50$ & $10: 40$ & $09: 45$ \\
\hline Cambio color en grano & $10: 10$ & $10: 55$ & $10: 00$ \\
\hline Hora salida de tostador & $10: 20$ & $11: 25$ & $10: 30$ \\
\hline Enfriado & $10: 30$ & $11: 30$ & $10: 33$ \\
\hline Molido & $10: 35$ & $11: 35$ & $10: 35$ \\
\hline Fin molido & $10: 40$ & $11: 39$ & $10: 40$ \\
\hline Pesado & $10: 50$ & $11: 45$ & $10: 45$ \\
\hline Sellado & $11: 00$ & $11: 50$ & $10: 50$ \\
\hline Fin de operación & $11: 20$ & $12: 25$ & $11: 30$ \\
\hline
\end{tabular}

Tabla 3.1 Resultados de tres operaciones - parte 1 Fuente: Elaboración propia

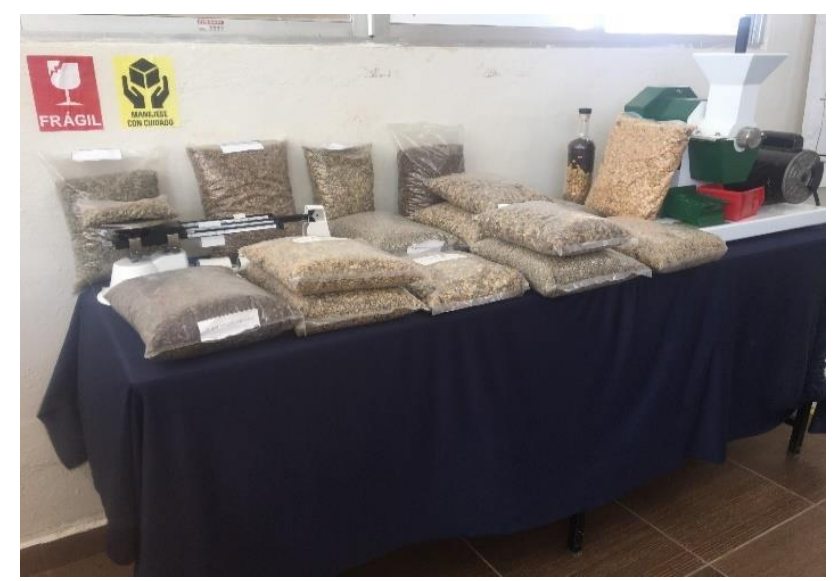

Figura 5 Estación de trabajo de pesado de grano verde, tostado y molido

Fuente: Laboratorio de Ingeniería Industrial de la Universidad Veracruzana

\begin{tabular}{|l|l|l|l|}
\hline \multicolumn{4}{|c|}{ Datos de muestras de $3 \mathrm{~kg} /$ ciclo en cada operación } \\
\hline \multicolumn{1}{|c|}{ Operación } & \multicolumn{1}{c|}{$\mathbf{1}$} & \multicolumn{1}{c|}{$\mathbf{2}$} & \multicolumn{1}{c|}{$\mathbf{3}$} \\
\hline Fecha & 18 Enero & 8 Febrero & 8 Marzo \\
\hline Tiempo de Inicio & $09: 25$ & $10: 10$ & $09: 30$ \\
\hline Fin de operación & $11: 20$ & $12: 25$ & $11: 30$ \\
\hline Peso inicial $(\mathrm{kg})$ & 3 & 3 & 3 \\
\hline $\begin{array}{l}\text { Temperatura mínima } \\
{ }^{\circ} \mathrm{C}\end{array}$ & 149 & 125 & 175 \\
\hline Temperatura máxima ${ }^{\circ} \mathrm{C}$ & 185 & 225 & 200 \\
\hline $\begin{array}{l}\text { Cantidad de bolsas }(0.5 \\
\mathrm{kg})\end{array}$ & 5 & 5 & 5 \\
\hline Peso final $(\mathrm{Kg})$ & 2.75 & 2.80 & 2.65 \\
\hline
\end{tabular}

Tabla 3.2 Resultados de tres operaciones - parte 2 Fuente: Elaboración propia

A continuación, se muestran imágenes de los trece tipos de granos evaluados en el proceso de tostado de acuerdo con la información obtenida en la primera etapa del proyecto del Cuerpo Académico UV-CA-470.

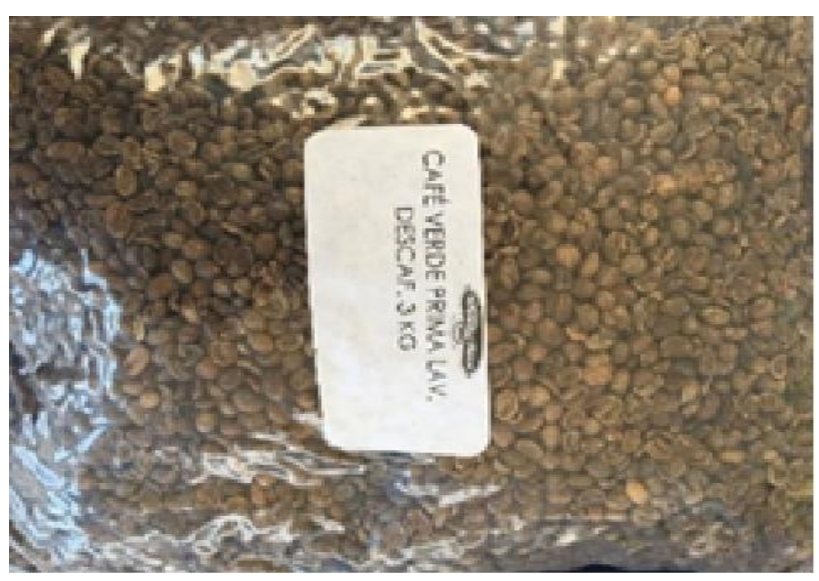

Figura 6 Café verde prima lavado descafeinado Fuente: Finca Monte Azul

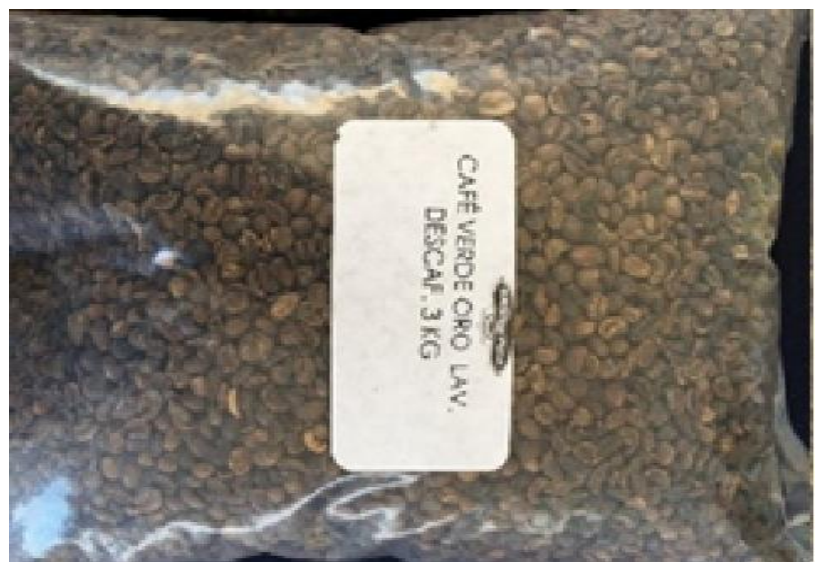

Figura 7 Café verde oro lavado descafeinado Fuente: Finca Monte Azul 


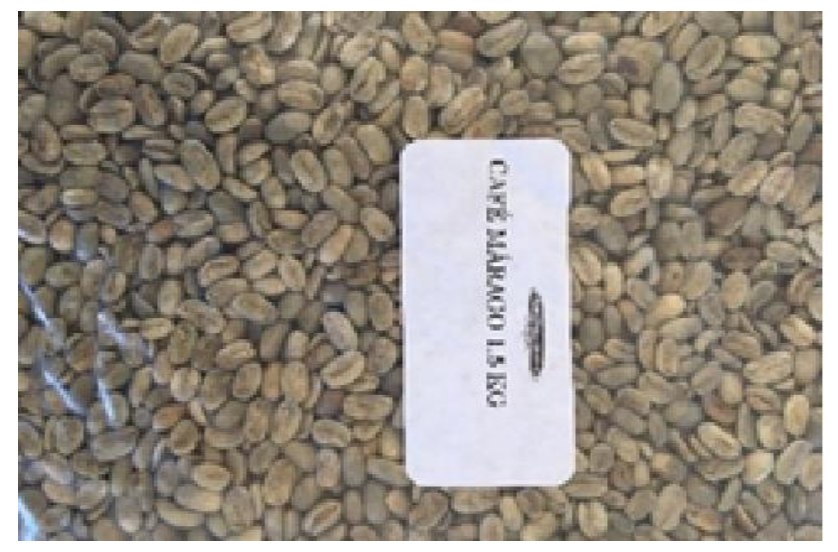

Figura 8 Café tipo Márago Fuente: Finca Monte Azul

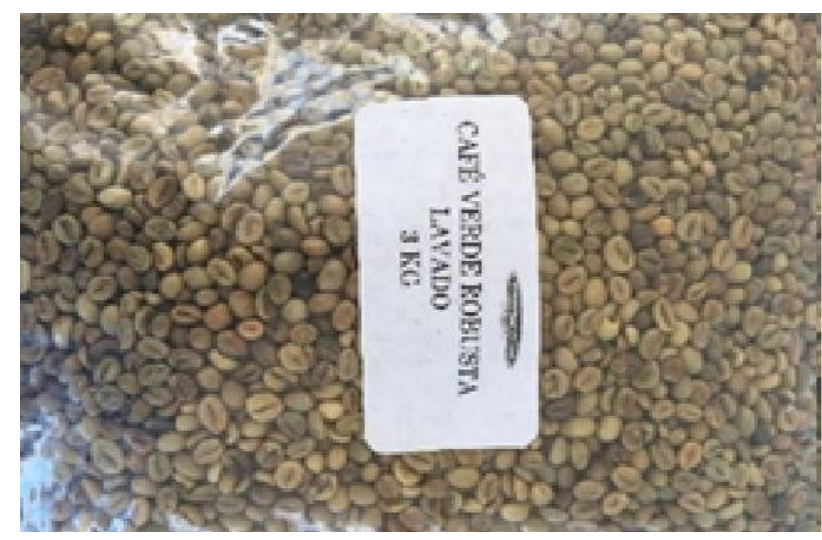

Figura 9 Café verde premium Fuente: Finca Monte Azul

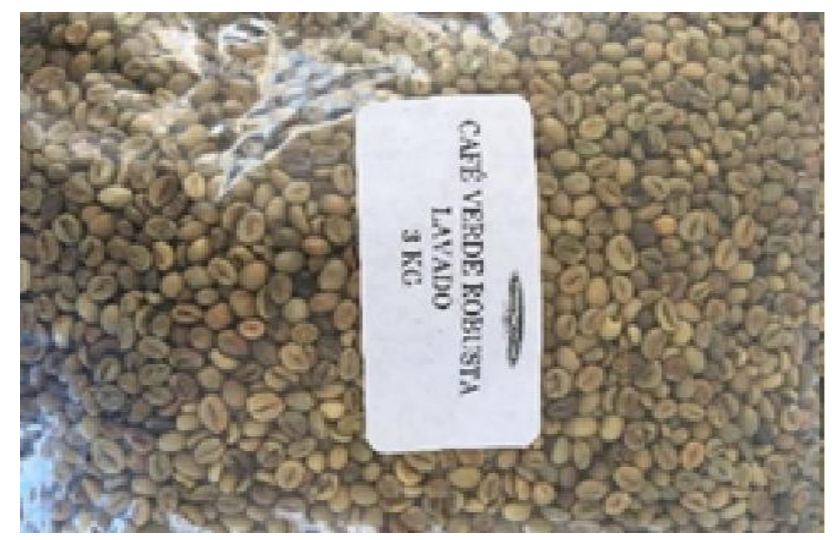

Figura 10 Café verde robusta lavado Fuente: Finca Monte Azul

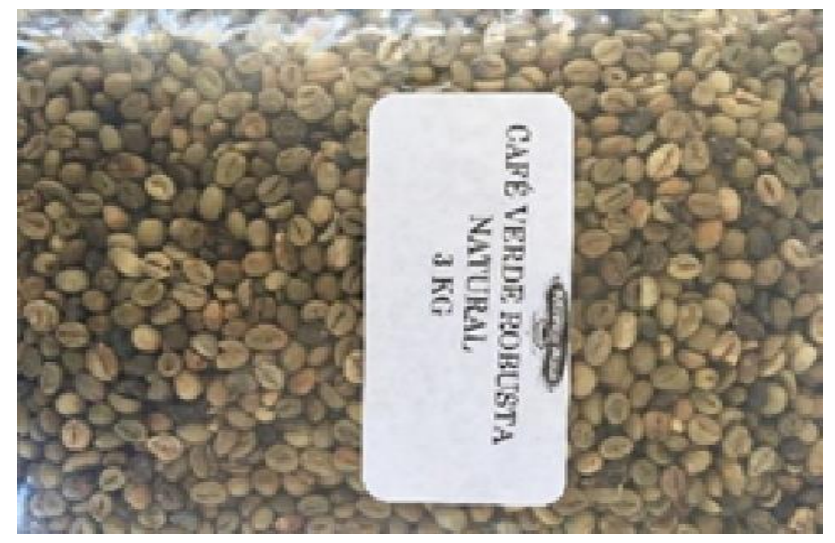

Figura 11 Café verde robusta natural Fuente: Finca Monte Azul

ISSN 2523-0344

ECORFAN® Todos los derechos reservados

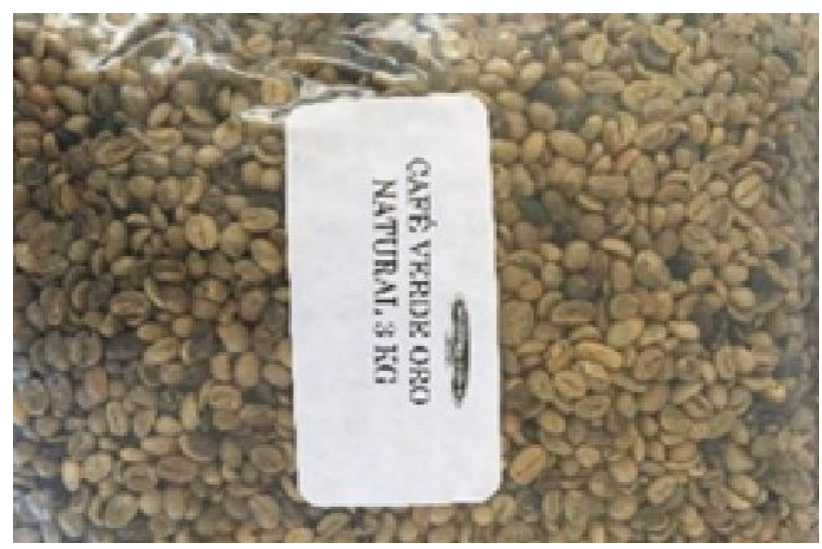

Figura 12 Café verde oro natural

Fuente: Finca Monte Azul

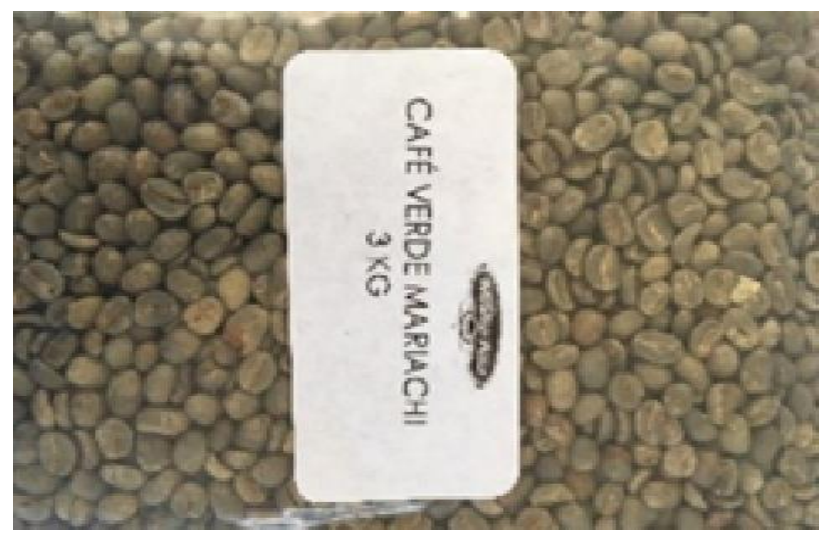

Figura 13 Café verde mariachi

Fuente: Finca Monte Azul

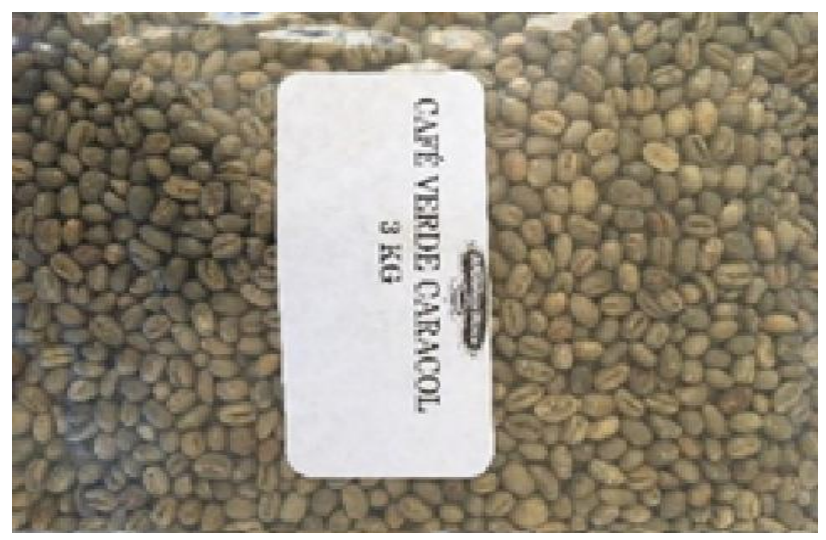

Figura 14 Café verde caracol

Fuente: Finca Monte Azul

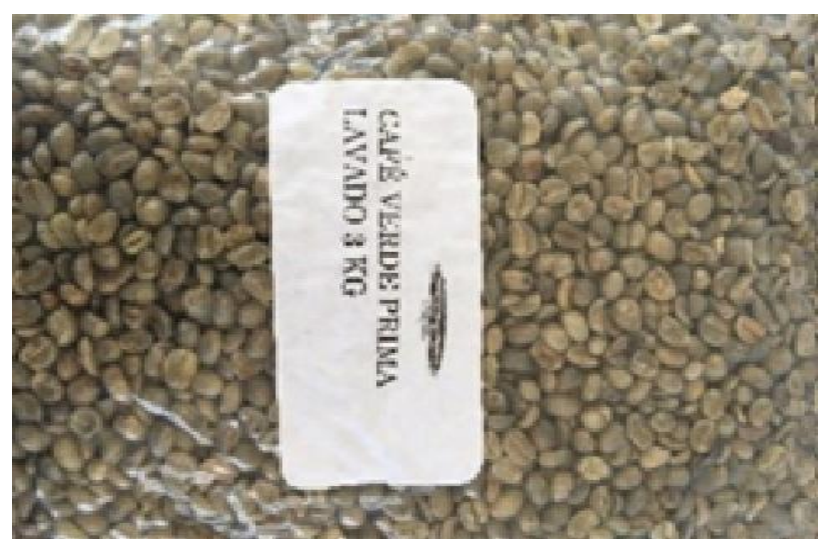

Figura 15 Café verde prima lavado

Fuente: Finca Monte Azul

RAMÍREZ-ROMÁN, Adolfo, SUÁREZ-ÁLVAREZ, Ángel, CHABATURANGA, Jacqueline y ORTIZ-MARTÍNEZ, Francisco. Análisis del tostado del grano de café. Revista de Ingeniería Industrial. 2019 


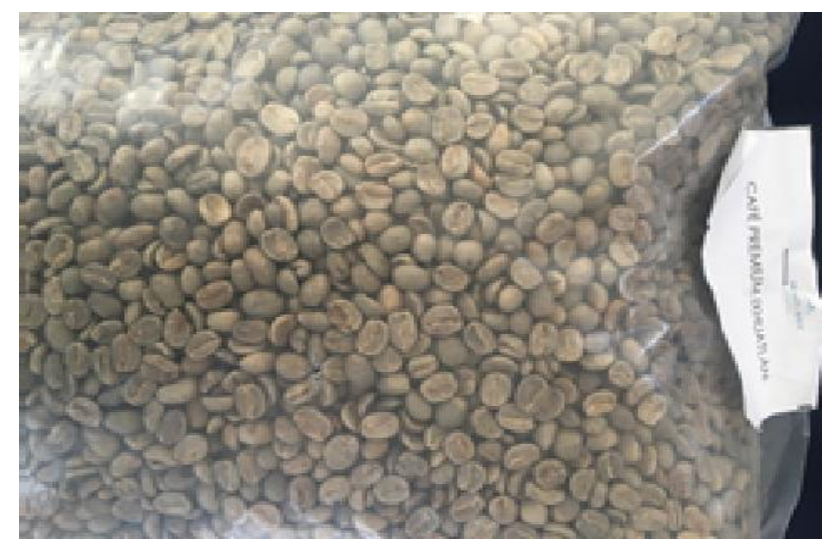

Figura 16 Café premium Ixhuatlán Fuente: Finca Monte Azul

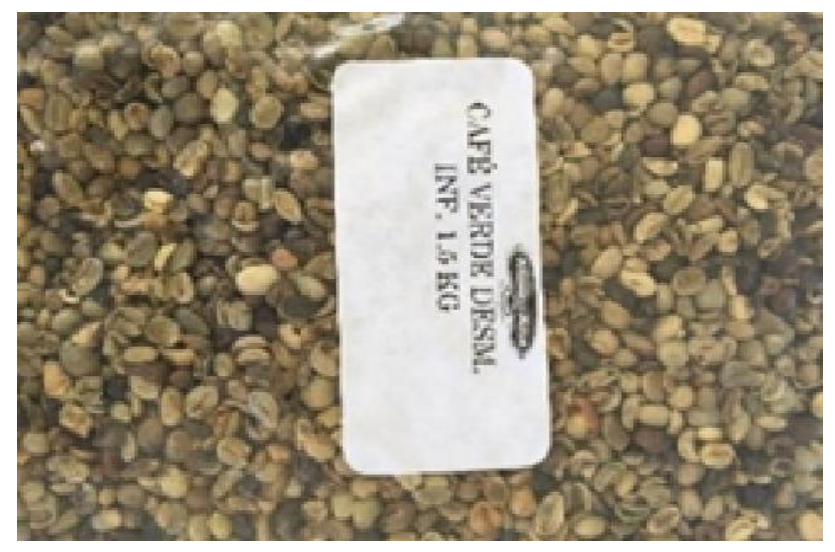

Figura 17 Café verde desmanchado Fuente: Finca Monte Azul

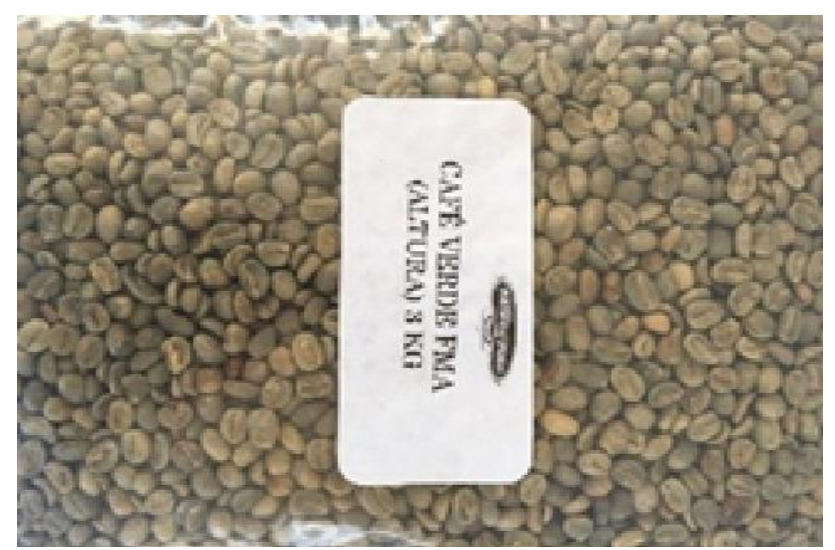

Figura 18 Café verde FMA (altura)

Fuente: Finca Monte Azul

En el periodo de Abril-Junio de 2019 se desarrolló lo siguiente:

Con referencia a la materia prima en el proceso de molido, en los ciclos de molido que se estudiaron se procesaron diferentes tipos de café tostado, con un cierto nivel de molido así que en algunos casos se podrá observar su nivel de molido y cantidad obtenida en los siguientes tres análisis representados por la tabla 3.3, 3.4, y 3.5.

\begin{tabular}{|l|r|r|}
\hline Café tostado oscuro & \multicolumn{1}{c|}{ Nivel } & \multicolumn{1}{c|}{ Cantidad } \\
\hline Premium & 7 & 500 gr. \\
\hline Mariachi & 7 & 500 gr. \\
\hline Caracol & 7 & 500 gr. \\
\hline Lavado FMA & 5 & 500 gr. \\
\hline
\end{tabular}

Tabla 3.3 Información representativa del proceso de molido en el análisis uno

Fuente: Elaboración propia

\begin{tabular}{|l|r|r|}
\hline Café tostado oscuro & \multicolumn{1}{c|}{ Nivel } & \multicolumn{1}{c|}{ Cantidad } \\
\hline Mariachi & 5 & 314 gr. \\
\hline Mariachi & 6 & 314 gr. \\
\hline Robusta Natural & 6 & 500 gr. \\
\hline Desmanchado & 6.5 & 314 gr. \\
\hline
\end{tabular}

Tabla 3.4 Información representativa del proceso de molido del análisis dos

Fuente: Elaboración propia

Nota: El Nivel se refiere el tamaño de grano obtenido por el molido donde 1 es fina y 9 es granular

\begin{tabular}{|l|r|r|}
\hline Café tostado oscuro & Nivel & \multicolumn{1}{c|}{ Cantidad } \\
\hline Oro & 7 & 260 gr. \\
\hline Oro descafeinado & 7 & 260 gr. \\
\hline Prima lavada descafeinado & 7 & 260 gr. \\
\hline Mezcla & 7 & 260 gr. \\
\hline
\end{tabular}

Tabla 3.5 Información representativa del proceso de molido del análisis tres

Fuente: Elaboración propia

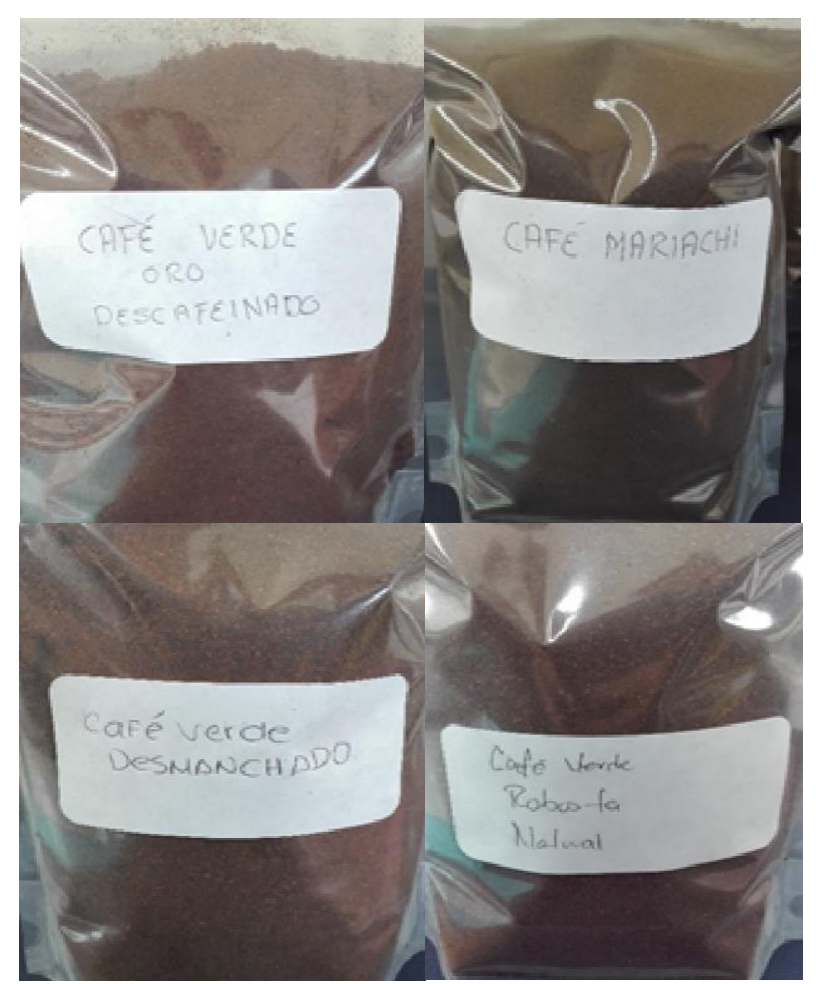

Figura 19 Cuatros muestras de café molido Fuente: Elaboración propia

Se elaboró un diagrama de las actividades del ciclo de operación (Ver Figura 20 y Tabla 3.8).

RAMÍREZ-ROMÁN, Adolfo, SUÁREZ-ÁLVAREZ, Ángel, CHABATURANGA, Jacqueline y ORTIZ-MARTÍNEZ, Francisco. Análisis del tostado del grano de café. Revista de Ingeniería Industrial. 2019 
Los primeros ciclos estudiados en cada proceso se realizaron con la finalidad de obtener tiempos preliminares para, poder calcular el tamaño de muestra, es por esta razón que solo se anotó la duración y una vez terminado el proceso se calcularon los tiempos finales. medición.

Fórmulas utilizadas durante el proceso de

Determinación del tamaño de la muestra por ciclo de tostado:

$n=\left(\frac{40\left(\sqrt{\left.\mathrm{n}^{\prime} \sum \mathrm{x}^{2}-\sum(\mathrm{x})^{2}\right)}\right.}{\sum \mathrm{x}}\right)^{2}$

Donde:

$\mathrm{n} \quad=$ número de observaciones

$40=$ Constante para un nivel de confianza de $94 \%$

n' = número de ciclos observados

$\sum \mathrm{x}=$ suma de los tiempos

$\mathrm{X} \quad=$ Valor de los tiempos en cada ciclo

$\sum \mathrm{x}^{2}=$ suma de los tiempos elevado al cuadro

Calcular el ritmo tipo y valoración de cada elemento (tostado, molido y envasado).

$T B=\frac{C V}{100}$

Donde:

$\mathrm{TB}=$ tiempo básico o tiempo normal

$\mathrm{C}=$ tiempo cronometrado o tiempo observado

$\mathrm{V}=$ valoración o calificación

$100=$ valor tipo de la escala .

Tiempo estándar de cada elemento: Se muestra un ejemplo de cálculo del tiempo tipo para el ciclo de molido de 314 gr de café tostado después de análisis de los suplementos en las operaciones:

$\begin{array}{ll}\text { Trabajo exterior } & =2.23 \mathrm{~min} \\ \text { Trabajo interior } & =0.38 \mathrm{~min} \\ \text { Suplementos por descanso } & =0.41 \mathrm{~min} \\ \text { Tiempo no ocupado } & =0.05 \mathrm{~min} \\ & \\ \text { Tiempo tipo } & =3.07 \mathrm{~min} \text { tipo }\end{array}$

$\mathrm{O}$ bien,

Trabajo exterior $\quad=2.23 \mathrm{~min}$

Tiempo condicionado máquina $=0.43 \mathrm{~min}$

Suplemento por descanso $\quad=0.41 \mathrm{~min}$

Tiempo tipo $\quad=3.07$ min tipo
Se determina el tiempo total de los elementos de trabajo externos, internos, los suplementos por descanso y el tiempo no ocupado en cada ciclo, la suma de estos da como resultado el tiempo estándar o tiempo tipo. Es necesario recordar que, en los ciclos de tostado al contar con tiempos no ocupados igual o mayores a $10 \mathrm{~min}$, el suplemento por descanso se utilizó dentro del ciclo de trabajo, por lo que no es necesario añadir el suplemento, como se muestra en los datos anteriores del ciclo de molido de 314 gr de café. Por lo cual, el tiempo tipo para los ciclos finales de tostado se indican a continuación:

$\begin{array}{ll}\text { Trabajo exterior } & =0.12 \mathrm{~min} \\ \text { Trabajo interior } & =3.621 \mathrm{~min} \\ \text { Suplementos por descanso } & =0.0 \mathrm{~min} . \\ \text { Tiempo no ocupado } & =36.529 \mathrm{~min} \\ \text { Tiempo tipo } & =40.27 \mathrm{~min} \text { tipo }\end{array}$

Debido la recolección de datos e información detallada de los componentes principales obtenidos, mediante la observación directa de los procesos de tostado, molido y envasado, al empleo de métodos estadísticos, herramientas de simplificación del trabajo y del estudio de tiempos, se logró estandarizar los métodos y tiempos de los tres procesos para un eficaz funcionamiento de los mismos, ya que para conseguir la eficacia, entre otras, es necesario establecer y tener pleno conocimiento del método y del tiempo que se requiere para su realización. El empleo de las técnicas y procedimientos mencionados, provocan la eliminación de actividades innecesarias y tiempos no ocupados, y con ello alcanzar mayor productividad, y en consecuencia incremento de la eficiencia, de las utilidades, la mejora en las condiciones de trabajo, etc., y un eficaz funcionamiento en el proceso de tostado, molido y envasado es necesario estandarizar el método de trabajo y el tiempo, el cual, el tiempo estándar de máquina en el proceso de tostado de los ciclos de precalentados se indican en la tabla 3.6 y 3.7.

\begin{tabular}{|l|c|}
\hline \multicolumn{1}{|c|}{ Elemento } & Tiempo en minutos \\
\hline $\begin{array}{l}\text { Tostador alcanza temperatura de } \\
\text { precalentado de } 200^{\circ} \mathrm{C} \text { a } 210^{\circ} \mathrm{C} .\end{array}$ & 14.3 \\
\hline $\begin{array}{l}\text { Tostador alcanza temperatura de } \\
\text { equilibrio. }\end{array}$ & 1.2 \\
\hline $\begin{array}{l}\text { Tostador alcanza temperatura de } \\
\text { tostado entre } 200^{\circ} \mathrm{C} \mathrm{a} 210^{\circ} \mathrm{C} .\end{array}$ & 8.3 \\
\hline Máquina termina de tostar. & 24.2 \\
\hline Termino de enfriamiento. & 3.4 \\
\hline
\end{tabular}

Tabla 3.6 Tiempos de la máquina en los ciclos de precalentado 


\begin{tabular}{|l|c|}
\hline \multicolumn{1}{|c|}{ Elemento } & Tiempo en minutos \\
\hline $\begin{array}{l}\text { Tostador alcanza temperatura de } \\
\text { precalentado de } 200^{\circ} \mathrm{C} \text { a } 210^{\circ} \mathrm{C}\end{array}$ & 2.9 \\
\hline $\begin{array}{l}\text { Tostador alcanza temperatura de } \\
\text { equilibrio }\end{array}$ & 1.8 \\
\hline $\begin{array}{l}\text { Tostador alcanza temperatura de } \\
\text { tostado entre } 200^{\circ} \mathrm{C} \text { a } 210^{\circ} \mathrm{C}\end{array}$ & 5.4 \\
\hline Máquina termina de tostar & 23.2 \\
\hline Termino de enfriamiento & 2 \\
\hline
\end{tabular}

Tabla 3.7 Tiempos de máquina en los ciclos siguientes Fuente: Elaboración propia
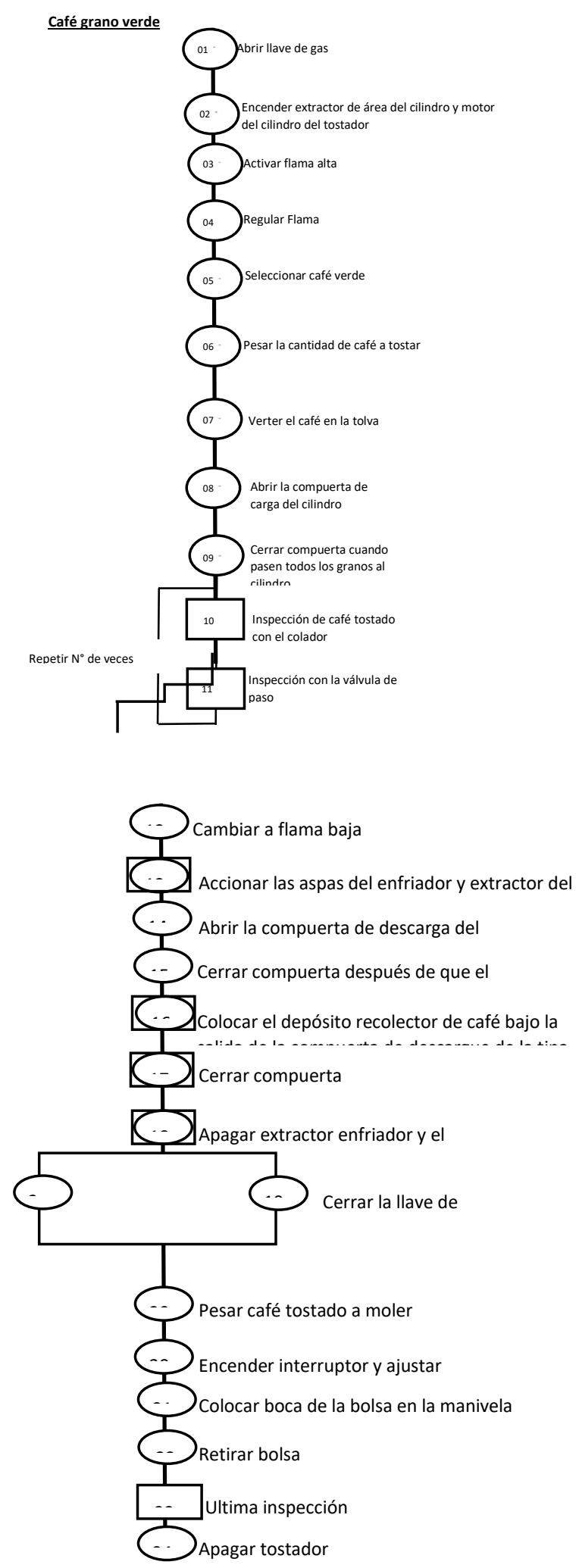

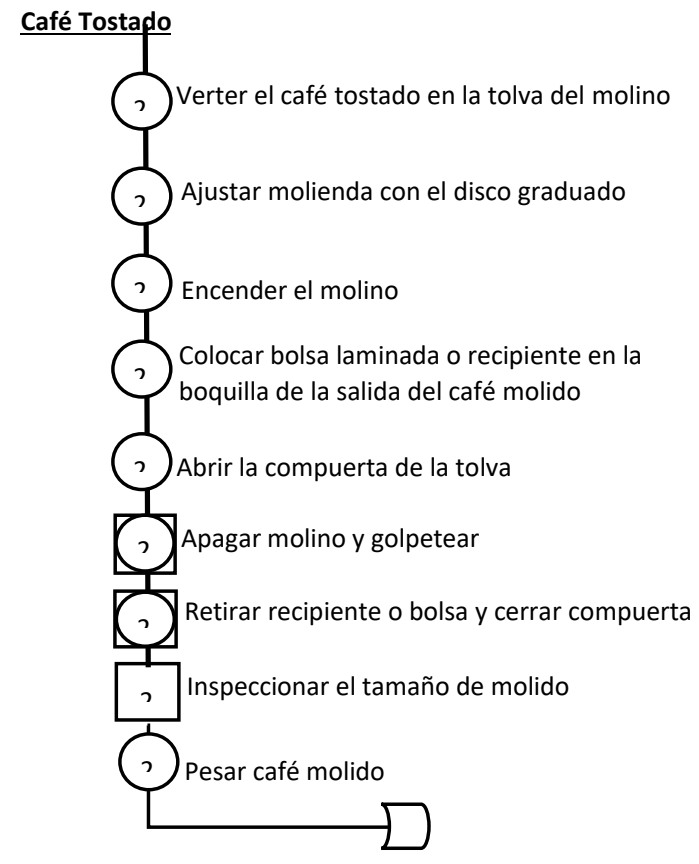

\begin{tabular}{|l|l|l|}
\hline \multicolumn{1}{|c|}{ Simbolo } & \multicolumn{1}{|c|}{ Actividad } & \multicolumn{1}{c|}{ Cantidad } \\
\hline & Operación & 24 \\
\hline$\square$ & Inspección & 4 \\
\hline$\square$ & Actividad combinada & $\mathbf{6}$ \\
\hline
\end{tabular}

Figura 20 Diagrama de proceso operativo para el proceso de tostado y molido de grano de café

Resultados de las hojas de análisis y recopilación de la información en el taller.

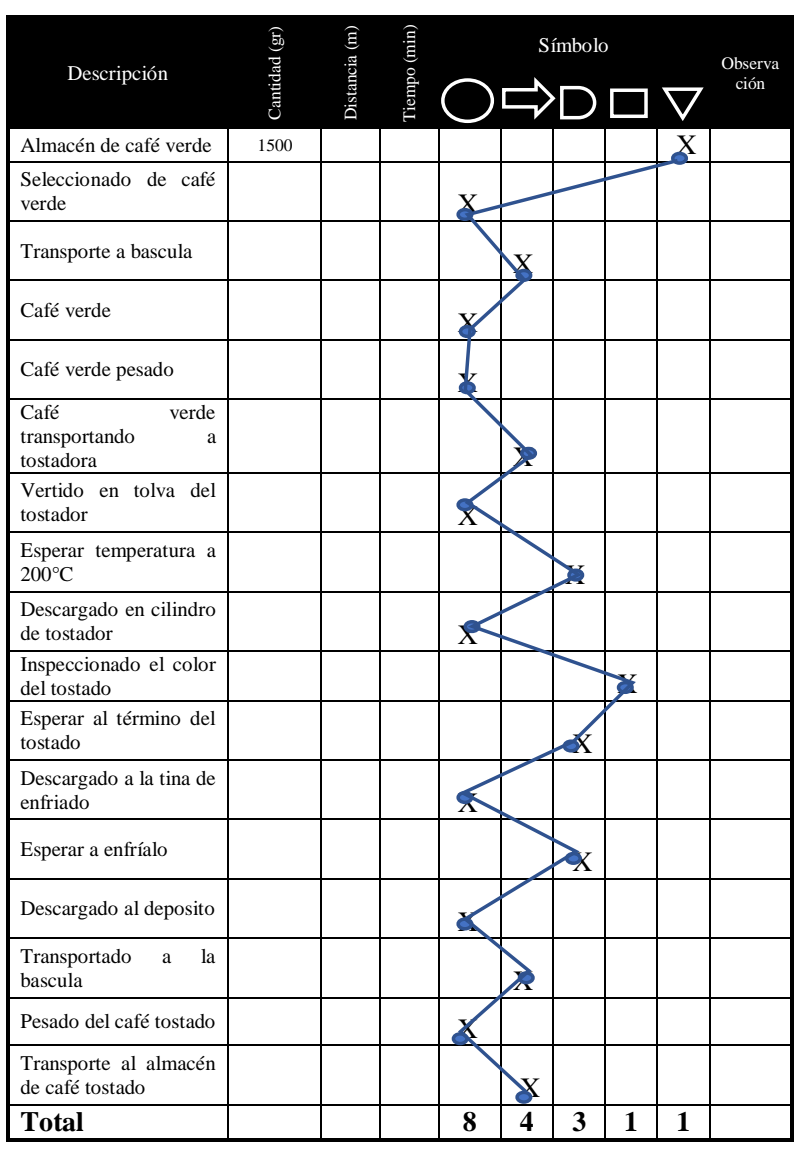

Tabla 3.8 Tabla de diagrama de operación del tostado

RAMÍREZ-ROMÁN, Adolfo, SUÁREZ-ÁLVAREZ, Ángel, CHABATURANGA, Jacqueline y ORTIZ-MARTÍNEZ, Francisco. Análisis del tostado del grano de café. Revista de Ingeniería Industrial. 2019 


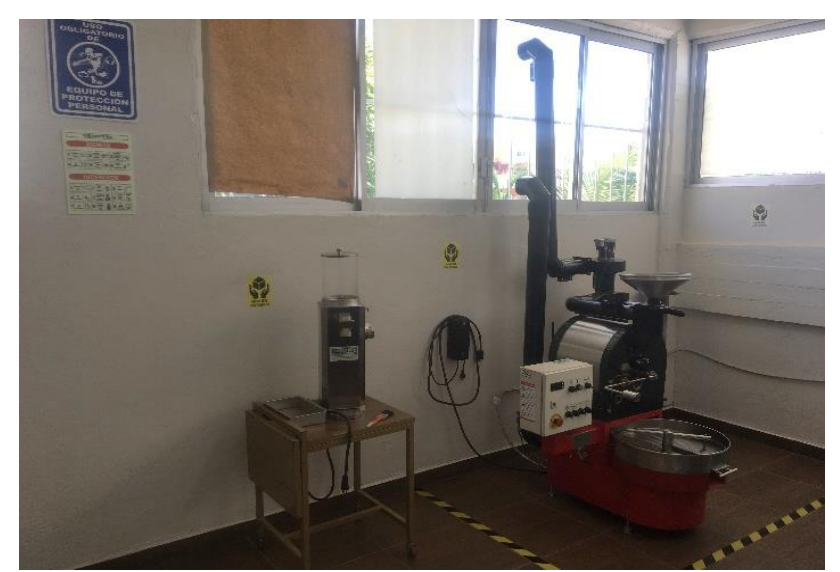

Figura 21 Área de tostado y molido de grano de café Fuente: Laboratorio de Ingeniería Industrial de la Universidad Veracruzana

De acuerdo con los resultados y actividades se generó el siguiente diagrama de bloque (ver figura 22) referente a la cadena de suministro del taller donde se establecieron los indicadores de compra y de producción que refiere a la cantidad de grano requerido para su tostado o molido, capacidad de cada máquina y sus respectivos ciclos por práctica de los estudiantes en el laboratorio.

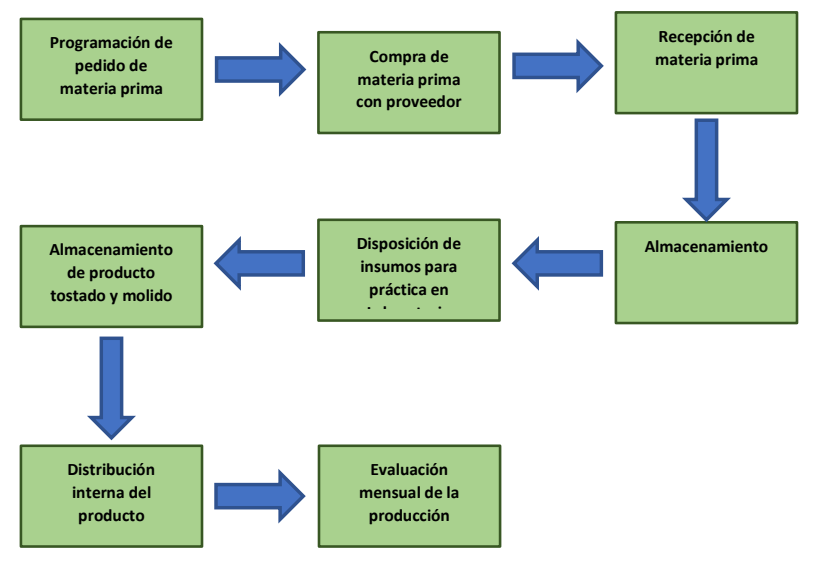

Figura 22 Diagrama de bloque Fuente: Elaboración propia

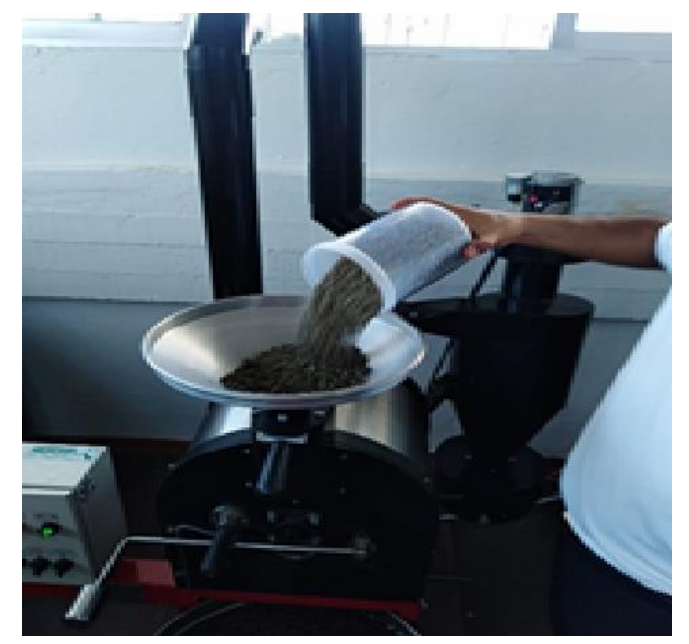

Figura 23 Vaciado de grano de café verde

Fuente: Laboratorio de Ingeniería Industrial de la Universidad Veracruzana
Para el desarrollo de las pruebas, se contempla la siguiente lista donde se describen los recursos utilizados en el proyecto para desarrollar estrategias de optimización de nuestro café veracruzano con las empresas productora y comercializadora de la región a través de convenios:

a) Báscula de precisión OHAUS 2610gr. Triple brazo. Modelo TJ2611. Plato de acero inoxidable. Sensibilidad 1 gr. Pesas de 500 y $1000 \mathrm{gr}$. Incluye cucharón de polipropileno.

b) Máquina mortero de muestras y rendimientos. Capacidad de 250 a 300gr. Motor de 1/2Hp.

c) Medidor Portátil de Humedad MAC PLUS. Marca Coffe Pro. Incluye: Estuche, batería, funda protectora y cable USB.

d) Juego de Zarandas para muestras de café. Marco de madera de 0.30 X $0.30 \mathrm{~m}$ Perforación redonda. 8 zarandas de 13/64 a 20/64 y \#0.

e) Charolas inoxidables para muestras de café

f) Molino SOLO CAFE modelo COATEPEC, Capacidad de $1.2 \mathrm{~kg} / \mathrm{min}$. Discos Suizos de 90 milímetros. Motor de $1 \mathrm{Hp}$. Fabricado en acero inoxidable y aluminio. Nueve niveles de granulometría, con opción a niveles intermedios para mayor precisión. Tolva de acrílico transparente con imán.

g) Selladora de pedestal electrónica FRL 350. Regulador de tiempo de sellado. Apoyo para bolsas. Mordaza de $35 \mathrm{~cm}$. Alimentación a 110v. Incluye kit de refacciones.

h) Tostador Profesional para café de $3 \mathrm{~kg} /$ Ciclo, Encendido electrónico, Ciclón recolector de tamos, Válvula solenoide de seguridad, Dos extractores con motores de 1/6Hp. Cilindro y Aspas con motorreductores de $1 / 6 \mathrm{Hp}$, Sistema de válvulas para Flama Alta y Baja. Tablero de controles con paro de emergencia. 


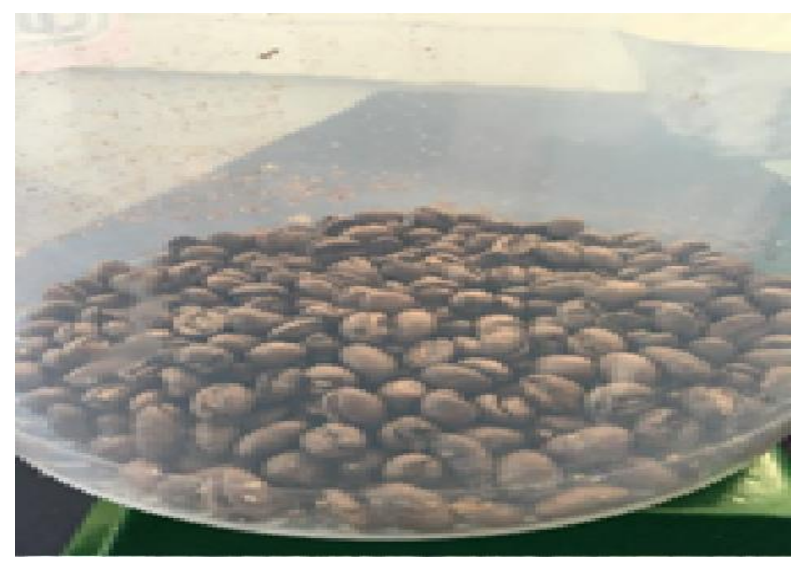

Figura 24 Grano de café tostado Fuente: Elaboración propia

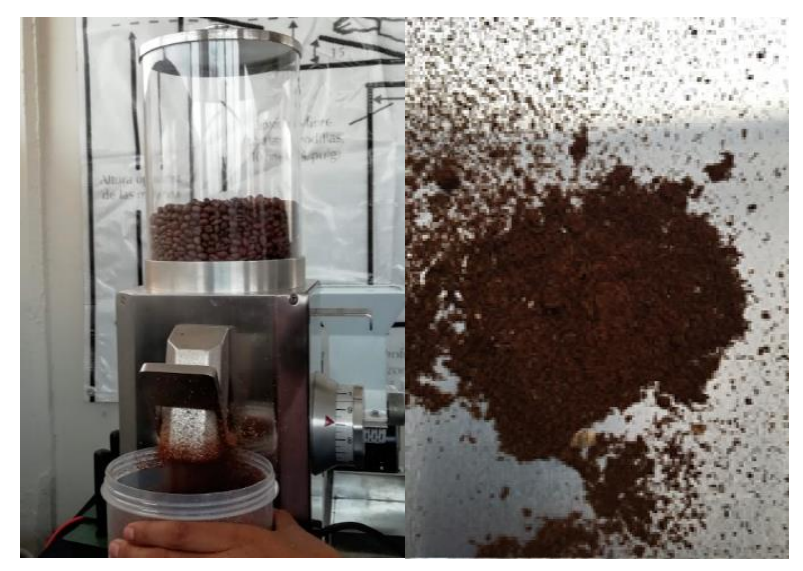

Figura 25 Grano de café molido Fuente: Elaboración propia

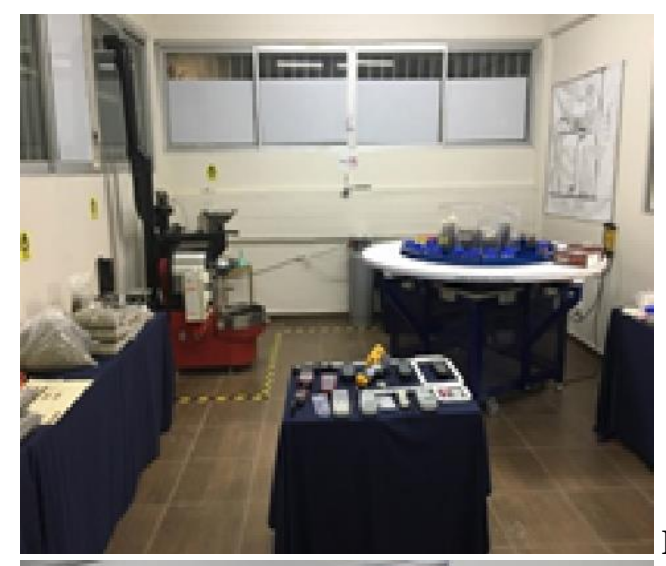

Figura 26a

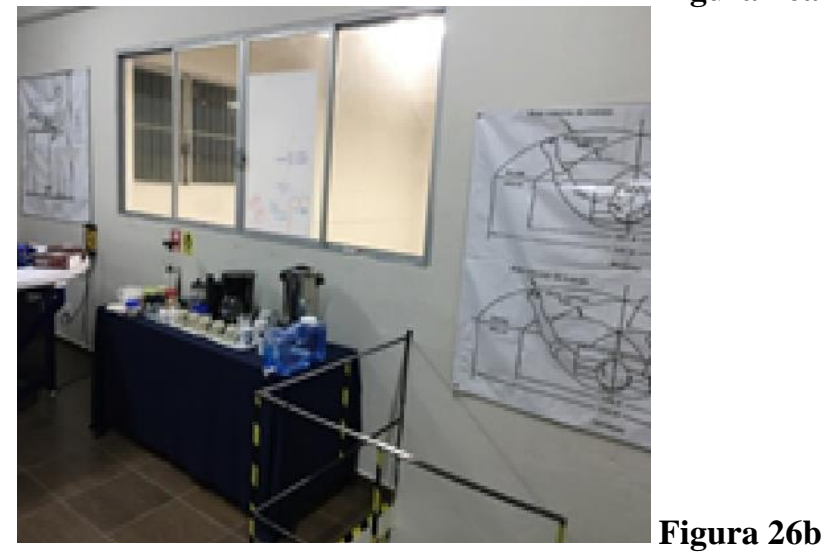

Figura 26b
Diciembre, 2019 Vol.3 No.10 1-16

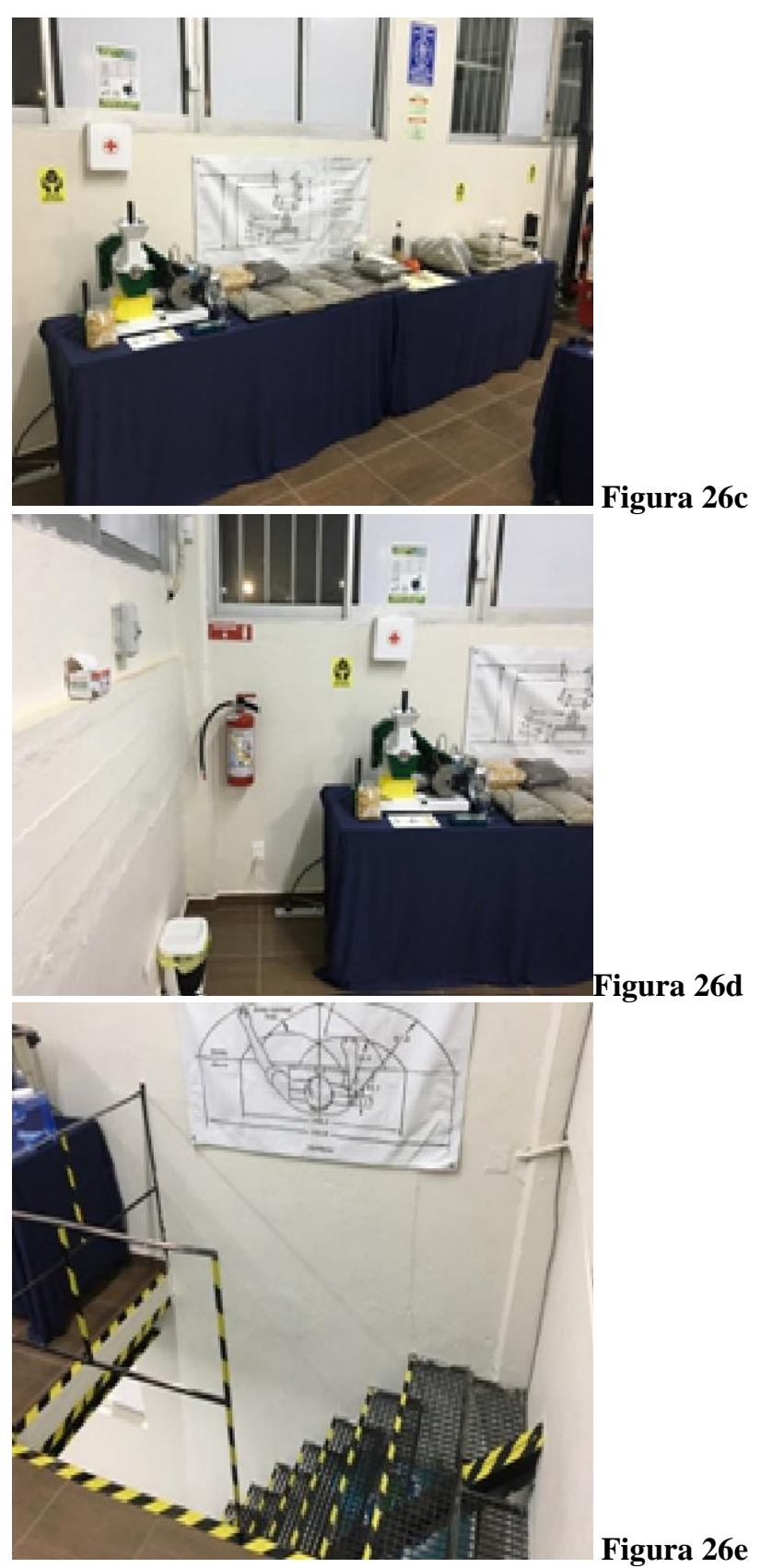

Figura 26 Áreas del Laboratorio de Ingeniería Industrial FIMCN (a, b, c, d, e)

Fuente: Universidad Veracruzana

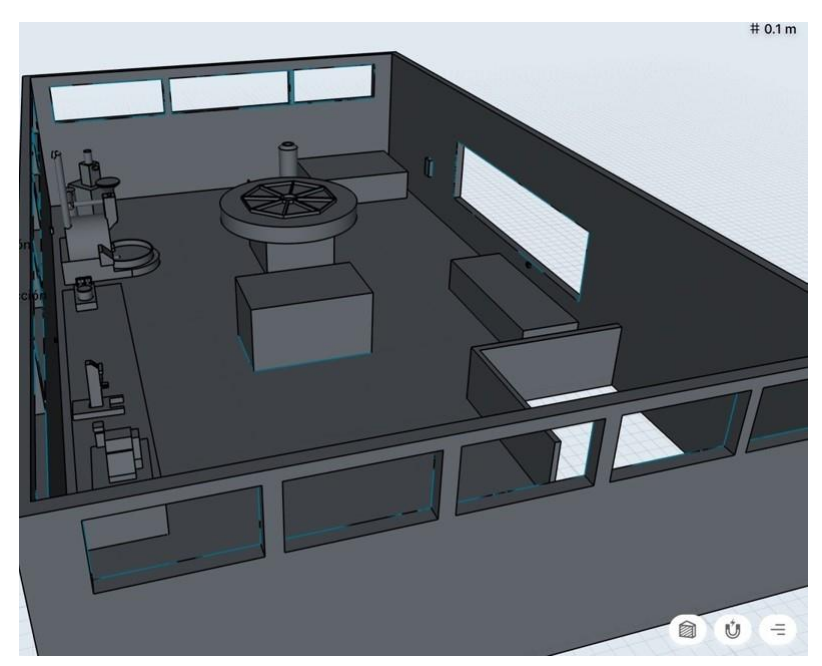

Figura 27 Distribución del Laboratorio

Fuente: Universidad Veracruzana

RAMÍREZ-ROMÁN, Adolfo, SUÁREZ-ÁLVAREZ, Ángel, CHABATURANGA, Jacqueline y ORTIZ-MARTÍNEZ, Francisco. Análisis del tostado del grano de café. Revista de Ingeniería Industrial. 2019 
De lo anterior indicado en las figuras, la mejora en los métodos como un producto de la intervención de la ingeniería, es un medio para obtener resultados confiables y generar un ambiente competitivo, también, con el desarrollo de las actividades, ya sea por prácticas de Taller, realización de tesis o con actividades complementarias dentro de las Experiencias Educativas del área Terminal y Optativas, entre otras experiencias del área disciplinaria (calidad, manufactura).

Por ejemplo, se desarrolló una propuesta de estructura de formato de práctica para el uso de los equipos o máquinas del área y generar información para su análisis de datos (Ver figura 29 en anexo); y, con referencia a las empresas visitadas en el trabajo de campo, está en proceso de formalizar convenio de colaboración para el desarrollo del proyecto en la segunda etapa (periodo Septiembre 2019 - Diciembre 2020) con las siguientes seis empresas y un municipio:

\section{- $\quad$ Café Díaz, S.A. \\ - $\quad$ Sólo Café de Calidad, S. de R.L. de C.V. \\ - $\quad$ Don Café, S.A. de C.V. \\ - $\quad$ Municipio de Ixhuatlán del Café \\ - Café-tal Apan \\ - Campo experimental de Café, Xico \\ - $\quad$ Finca Monte Azul, S.A. de C.V.}

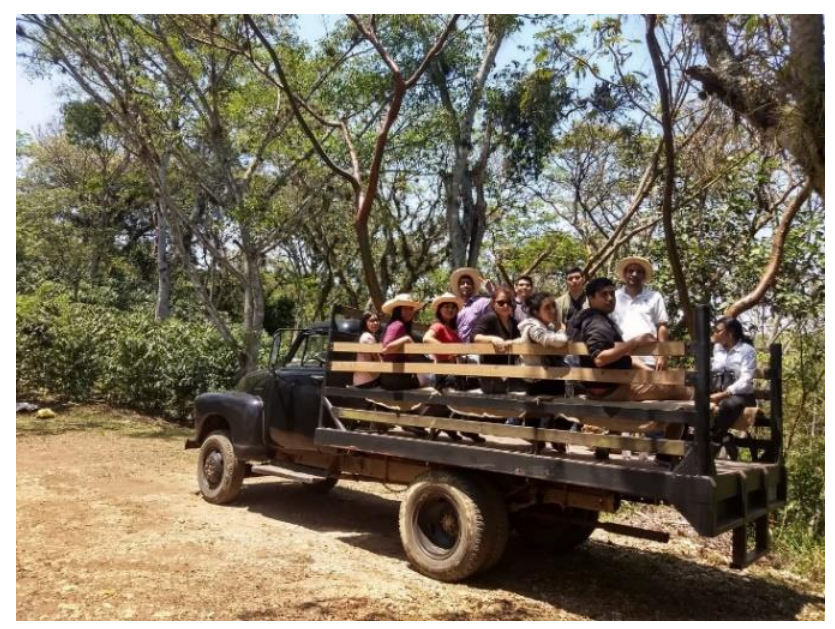

Figura 28 Trabajo de Campo

Fuente: Elaboración propia

\section{Anexo}

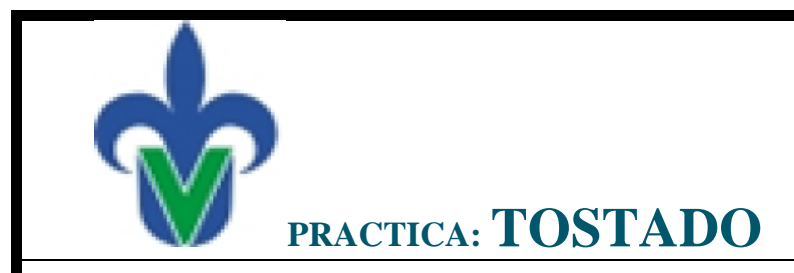

Integrantes del equipo:

\begin{tabular}{|c|c|}
\hline N. ${ }^{\circ}$ Sesión & 01 \\
\hline Fecha & 2019 \\
\hline $\begin{array}{c}\text { Experiencia } \\
\text { Educativa }\end{array}$ & Métodos \\
\hline
\end{tabular}

\section{Objetivo}

Identificar durante el tueste la función de las características de la materia prima y los parámetros del proceso, ver los importantes cambios físicos en el café y la formación de las sustancias responsables de las cualidades sensoriales del café. Teniendo en cuenta que, a lo largo del proceso, el grano gana un $100 \%$ de volumen, disminuye entre un $12 \%$ y un $20 \%$ su peso y pierde alrededor del $10 \%$ de su cafeína.

Café, Tueste, Tipo de tueste Conceptos

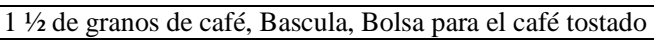

\section{Procedimiento}

Verificar compuerta y suministro de gas

Suministrar materia prima

Inspeccionar flama

Vaciar

Monitorear temperatura

Verificar muestras

Control de flama y temperatura

Apertura de compuerta y vaciado de grano tostado

\section{Cuestionario}

Instrucciones. Resuelve las siguientes preguntas.

¿A qué temperatura tiene que llegar la máquina para poder verter el grano de café?

¿A cuántos grados baja la temperatura cuando se empieza a tostar el café?

¿Qué tiempo se requiere para un tostado optimo en cada ciclo de café? ¿Cuánto tempo se debe de esperar entre cada ciclo?

¿Cuántas muestras salieron en cada ciclo?

\section{Conclusiones}

Instrucciones. Anota en este apartado tus conclusiones respecto a la

práctica.

Figura 29 Formato de práctica

Fuente: Elaboración propia

\section{Agradecimiento}

La gestión del personal directivo y administrativo de la Facultad de Ingeniería Mecánica y Ciencias Navales, e integrantes del Cuerpo Académico UV-CA-470 Innovación en Sistemas de Gestión con el proyecto de fortalecimiento "análisis y evaluación de las operaciones e innovaciones del proceso productivo del café" y la invaluable labor de los estudiantes tesistas y de trabajo recepcional para el desarrollo de la primera etapa del proyecto conformado por los siguientes siete estudiantes:

Judith Guadalupe Hernández Mena con el estudio de tiempo del tostado, molido y embazado 
$\checkmark \quad$ Itzel Viridiana Contreras Carbajal, con el manual de prácticas del laboratorio,

$\checkmark \quad$ Sofia Pensado Osorio con el análisis del contexto organizacional,

$\checkmark \quad$ Kevin Alexis de Jesús Carmona López con el estudio de indicadores en las operaciones de cadena de suministro,

$\checkmark \quad$ Jonathan Domínguez Garcés con el manual de seguridad,

$\checkmark \quad$ Isidro Jesé Xiguil Guexpal, con el análisis de problemáticas y desarrollo de la industria del café, y

$\checkmark \quad$ Erika Guillen González con el análisis de parámetros de procesos de transformación del grano del café.

\section{Conclusiones}

El café como modelo de análisis de referencia generó metodologías, estándares, técnicas y se consideraron el uso de buenas prácticas de otro sector industrial (vinícola) a través de su gestión en el taller de ingeniería de métodos y su respectiva optimización de los conocimientos de las Experiencias Educativas, es un balance en el desarrollo local y contexto de las organizaciones promoviendo el consumo del café regional. Así mismo el fortalecimiento de la vinculación a través de:

La gestión y apertura de espacios para la formación integral y académica del alumno y/o actividad sustantiva del académico.

La implementación sistemática de acciones con alternativas de solución a los problemas del entorno mediante la investigación de campo, la innovación y del desarrollo tecnológico, con la finalidad de divulgar la ciencia, la cultura, y el arte del Café.

La prestación de servicios que implican la consecución de recursos externos y, la transmisión directa de conocimientos hacia individuos, grupos o instituciones externas a la Universidad a través de la asesoría y curso de capacitación del Programa de Educación Continua.

La recopilación de buenas prácticas obtenidas en el proyecto del Café para el desarrollo de modelo de gestión.

$\mathrm{Y}$, con referencia al acondicionamiento y mejora del área de operación del laboratorio se tienen los siguientes resultados:
Con la observación in situ, de los procesos de tostado, molido y envasado de café, tanto en el Taller de Ingeniería de Métodos como en el trabajo de campo en la Finca de Guadalupe en Córdoba, Finca Monte Azul en Huatusco, en la Finca de Campo experimental en Xico, y en la finca del Café-tal Apan, se estableció un método para los tres procesos, y en consecuencia el tiempo estándar que se necesita para llevarlos a cabo.

Con la elaboración del diagrama de proceso operativo para el tostado, molido y envasado, se estableció la descripción, clasificación y la secuencia a detalle de las operaciones que se llevan en cada actividad.

Mediante las observaciones preliminares de los ciclos de trabajo de cada proceso se determinaron $\mathrm{y}$ describieron los tiempo $\mathrm{y}$ actividades.

Con el uso de la técnica "estudio de tiempos", mediante el método de "cronometraje acumulativo", se obtuvo la cantidad de trabajo expresada en minutos para cada ciclo de proceso.

Al realizar la descripción del método, se pudieron simplificar los tiempos no productivos ya que antes en los registros de observaciones preliminares, al no contar con un método establecido, se ejecutaban acciones innecesarias.

Una vez determinado el método de trabajo y realizado el cronometraje de cada elemento, se calificó el ritmo tipo o desempeño del trabajador mediante el método de velocidades. Los tiempos tipo se pudieron determinar, una vez obtenidos los tiempos básicos para los elementos de trabajo internos y externos, junto con el tiempo de la máquina, más el cálculo para los suplementos por descanso.

En los suplementos por descanso para los ciclos de tostado, los cuales presentaron minutos inactivos iguales o mayores a $10 \mathrm{~min}$, se pudieron utilizar dentro del mismo, por el contrario, para los ciclos de molido y envasado al ser más cortos, dichos suplementos se tuvieron que agregar fuera del ciclo de trabajo.

Posterior a la obtención de tiempos y establecido el método para los procesos de tostado, molido, se crearon los diagramas de flujo del material y operario, con el propósito de representar el tratamiento del café. En el caso del flujo de operario las acciones a ejecutar.

RAMÍREZ-ROMÁN, Adolfo, SUÁREZ-ÁLVAREZ, Ángel, CHABATURANGA, Jacqueline y ORTIZ-MARTÍNEZ, Francisco. Análisis del tostado del grano de café. Revista de Ingeniería Industrial. 2019 
Consecuentemente al estudio de tiempos se obtuvo información para su estándar, correspondiente a los tiempos de maquina dentro del proceso de tostado como: los minutos de la tostadora para alcanzar la temperatura de precalentado, temperatura de equilibrio, en adquirir la temperatura de tueste, duración del tostado y tiempo de enfriado.

Con la medición del trabajo se observó que los ciclos de trabajo en el proceso de tostado presentaron mucha diferencia entre sí, tanto en los ciclos de precalentado, como en los subsecuentes a él, uno de los factores más importantes que provoca dicho contraste, fue la regulación de la flama en la tostadora, el tamaño del grano, su uniformidad en color, su tipo de secado, o el tipo de combinaciones en cuanto a la altura, humedad, nutrientes y minerales de la tierra.

\section{Referencias}

Auletta, N., \& Ojeda, E. (2014). Desafíos de la innovación empresarial en américa latina. (Spanish). Debates IESA, 19(2), 10-14.

Córdoba-Castro, N. M., \& Guerrero-Fajardo, J. E. (2016). Caracterización de los procesos tradicionales de fermentación de café en el departamento de Nariño. (Spanish). Biotecnología En el Sector Agropecuario y Agroindustrial, 14(2), 75-83. doi:10.18684/BSAA(14)75-83.

Del Carmen Camas-Pascacio, A., \& VelázquezPompeyo, R. I. (2014). Un café por los pequeños productores, el escalamiento productivo y el desarrollo local. (Spanish). Revista Chilena de Economía y Sociedad, 8(1/2), 12-32."el estado debe compartir con los productores de café los planes para enfrentar la crisis económica". (Spanish). (2009). Agro Enfoque, 22(162), 3638.

Farro, C., Enrique, M., \& De la Cruz Mora, W. (2019). Efecto hipoglicemiante de los extractos hidroalcohólicos de los granos verdes y granos tostados de Coffea arabica L."café" en Rattus rattus var. albinus con hiperglicemia inducida.

Fernández, E. M., \& Mejía, F. E. (2007). Modelo de administración para la operación sustentable y gestión de la calidad en las agroindustrias de café: estudio de caso. (Spanish). Ingeniería Industrial, 28(3), 14-24.
Ferro-Soto, C., \& Mili, S. (2013). Desarrollo rural e internacionalización mediante redes de Comercio Justo del café. Un estudio del caso. (Spanish). Cuadernos de Desarrollo Rural, 10 (72), 267-289.

Finca Monte Azul. (s.f.). Obtenido de http://fincamonteazul.com/. Recuperado el 24 de abril de 2019

Flores, P., \& Keni, J. (2019). Influencia de tres pisos altitudinales en las características físicas y sensoriales del café (Coffea arábica L.) variedad Catimor en los distritos de Lamas y Alonso de Alvarado Roque.

Freivalds, Andris (2014). Ingeniería industrial de Niebel: Métodos, estándares y diseño del trabajo. México: Mc Graw Hill.

Garcia, N., \& Rossel, E. (2019). Evaluación de la productividad y calidad en taza de la variedad de café Costa Rica 95 (Coffea Arabica L.) en el sector de Timaruca, en la provincia de San Ignacio-Cajamarca.

Hammelburg, O. (2007). El camino del café la calidad. (Spanish). Agro enfoque, 21(156), 3435 .

Herrera, J. C., Medina, S. M., Beleño, K., \& Gualdrón, O. E. (2016). Diseño de un sistema automático de selección de frutos de café mediante técnicas de visión artificial. (Spanish). UIS Ingenierías, 15(1), 7-14. doi:10.18273/revuin. v15n1-2016001.

INEGI. (2019). Censos Económicos. Obtenido de https://www.inegi.org.mx/programas/ce/2019/. Recuperado el 21 de abril de 2019

Innovación en la industria de café calidad y tiempo de vida útil del café tostado tipo premium. (Spanish). (2014). Agro Enfoque, 29 (193), 8-10.

Interno Promover el consumo del café de calidad y mejorar su productividad en el campo. (Spanish). (2011). Agro Enfoque, 27 (179), 1820.

La problemática del café. (Spanish). (2007). Agro Enfoque, 21 (156), 14-15. 
Llanos, R. A. (2007). Factores claves en las alianzas universidad - industria como soporte de la productividad en la industria local: hacia un modelo de desarrollo económico y social sostenible. (Spanish). Investigación Y Desarrollo, 15 (1), 208-225.

Maynard, Harold. (2018). Manual del ingeniero Tomp I y II, 5a . Ed. México: McGraw-Hill.

Maya, G., César, J., \& Piedrahita Jaramillo, A. (2019). Influencia de las características del empaque y la etiqueta en la percepción del consumidor de café.

Mendoza, M. E. (2009). Café y cultura productiva en una región de Veracruz. (Spanish). Nueva Antropología: Revista De Ciencias Sociales, 22(70), 33-56.

Ortiz-Triana, V. K., \& Caicedo-Rolón, Á. J. (2015). Procedimiento para la programación y control de la producción de una pequeña empresa. (Spanish). Revista Ingeniería Industrial, 14 (1), 49-104.

Oliveros-Tascón, C. E., \& Sanz-Uribe, J. R. (2011). Ingeniería y café en Colombia. (Spanish). Revista De Ingeniería, (33), 99-114.

Torres-Valenzuela, L. S., Martínez, K. G., Serna-Jimenez, J. A., \& Hernández, M. C. (2019). Secado de Pulpa de Café: Condiciones de Proceso, Modelación Matemática y Efecto sobre Propiedades Fisicoquímicas. Información tecnológica, 30 (2), 189-200.

Universidad Veracruzana (2018). Programa de Trabajo Estratégico (PTE) 2017-2021. Pertenencia y Pertinencia. Recuperado de https://www.uv.mx/documentos/programa-detrabajo/. Recuperado el 17 de Mayo de 2019. 